\title{
INQUÉRITO SOROLÓGICO DE SARAMPO EM CRIANÇAS DE 5 A 15 MESES DE IDADE, EM CURITIBA E SÃO JOSÉ DOS PINHAIS, ESTADO DO PARANÁ, BRASIL, 1983*
}

\author{
Miguel Angel Lino Rodriguez** \\ Irene Skraba** \\ Eliane Pereira Maluf** \\ Eleusis Ronconi Nazareno*** \\ Albênia Paiva Cavalcanti**** \\ Nádia Pádua de Mattos**** \\ Orlei Cabrine**
}

\begin{abstract}
RODRIGUEZ, MA.L. et al. Inquérito sorológico de sarampo em crianças de 5 a 15 meses de idade, em Curitiba e Săo José dos Pinhais, Estado do Paraná, Brasil, 1983. Rev. Saúde públ., S. Paulo, 18: 421 - 8, 1984.
\end{abstract}

\begin{abstract}
RESUMO: Inquérito sorológico, realizado para avaliar os motivos da alta incidência e surtos frequlentes de sarampo nas cidades de Curitiba e Sśo José dos Pinhais - Paraná (Brasil), revela que entre 7 e 10 meses de idade só $44 \%$ das crianças vacinadas estáo protegidas e que entre o 11 e e 159 mês o indice de proteçăo se eleva para $65,1 \%$. As nšo vacinadas, ao $59,6 \%$ e 70 mês de idade apresentaram percentuais de proteção de $56,7,28,6$ e 14,8, respectivamente. As crianças que foram vacinadas ao 79 e 80 més apresentaram percentuais de proteçáo de 50,8 e as vacinadas a partir do 90 mEs, de 75,75\%. As médias geométricas dos títulos de anticorpos também foram menores nas vacinadas antes dos 9 meses, em relaçăo às vacinadas a partir desta idade.
\end{abstract}

UNITERMOS: Sarampo, prevençăo e controle. Inquéritos sorológicos.

\section{INTRODUÇAO}

Um dos problemas que tem preocupado a vigilância epidemiológica do Paraná é a alta incidência de sarampo (Fig. 1). Isto, mesmo nas áreas onde se tem obtido elevada cobertura vacinal, o que mostra que a estratégia do atual programa náo vem logrando o éxito esperado.

No município de Curitiba, a vacina utilizada e de qualidade controlada. A potência é comprovada laboratorialmente e fatores como prazo de validade, diluição correta, náo exposição a luz e temperatura ideal sáo bem controlados ${ }^{14}$. Isto sempre sugere que há fatores do receptor contribuindo para a

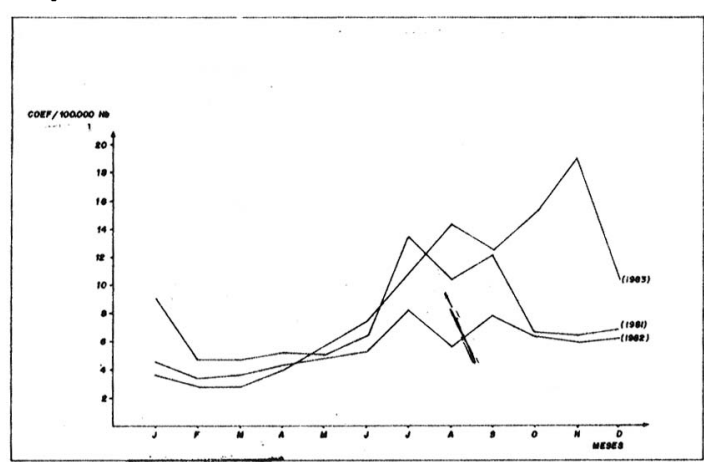

Fig. 1 - Inciđência mensal de sarampo no Paraná - 1981-1983. baixa eficácia da vacinaç̃̃o.

- Trabalho apresentado no XX Congresso da Sociedade Brasileira de Medicina Tropical, Salvador (Bahia), 1984.

* Do Laboratório de Pesquisas Biológicas da Fundação de Saúde Caetano Munhoz da Rocha - Rua Ubaldino do Amaral, 545 - 80000 - Curitiba, PR - Brasil.

*** Do Departamento de Epidemiologia e Controle de Doenças da Fundação de Saúde Caetano Munhoz da Rocha - Curitiba, PR - Brasil.

**** Do Grupo de Planejamento e Controle da Fundação de Saúde Caetano Murihoz da Rocha - Curitiba, PR - Brasil. 
RODRIGUEZ, M.A.L. et al. Inquérito sorológico de sarampo em crianças de 5 a 15 meses de idade, em Curitiba e São José dos Pinhais, Estado do Paraná, Brasil, 1983. Rev. Saride públ, S. Paulo, 18:421-8, 1984.

Sabe-se que os anticorpos adquiridos passivamente de origem materna, que proporcionam proteção às crianças contra a doença durante os primeiros meses de vida, interferem com o desenvolvimento da imunidade ao sarampo pela vacinação ${ }^{1,3}, 4,5,6,7,8,11$, $13,15,16,18,19$, e que a idade em que ocorre o declínio desses anticorpos varia para diferentes regioes ${ }^{y}$. Na América Latina, aparentemente a mortalidade é precoce e a quase totalidade dos óbitos ocorrem em menores de 3 anos $^{12}$.

Um estudo realizado no Quênia ${ }^{13}$, revelou que $92 \%$ de crianças aos 7,5 meses de idade ño possuiam anticorpos passivos e $90 \%$ das mesmas apresentavam soro conver. são quando vacinadas nesta idade. 0 mesmo estudo refere outros trabalhos feitos na Rodésia, África do Sul e Taiwan em que as taxas máximas de conversáo foram encontra. das aos 9 meses de idade.

Para se determinar a melhor idade para imunização com vacina anti-sarampo o ideal é a realização de estudos independentes em cada área.

No Brasil, a preocupação com a gravidade dos casos de sarampo, em crianças menores de 12 meses $^{10,16}$, levou o Ministério da Saúde em 1973, a recomendar a vacina anti-sa. rampo a partir dos 8 meses. Posteriormente, em 1975, a idade foi reduzida para 7 meses $^{2}$. Tal procedimento, porém, não parece ter sido capaz de controlar a doença nem alte. rar sua distribuição etária*.

Deve-se levar em conta que a fonte de infecção dos casos de sarampo que ocorrem, antes de um ano de idade, é constituída de crianças maiores de um ano.

Sabe-se que a eficácia da vacina é baixa quando aplicada antes dos 9 meses, e que, praticamente, não há transmissáo de sarampo entre menores de um ano. Assim, para proteger as crianças que náo atingiram a idade de vacinação é necessário diminuir ou eliminar a fonte de infecção que representam os maiores de um ano, através de altas cober- turas vacinais e elevados percentuais de proteção.

Em função disto, em 1983, o Ministério da Saúde recomendou 9 meses como a idade mínima para a vacinação anti-sarampo. Não obstante, o Estado do Paraná continuou com a vacinação aos 7 meses de idade.

$\mathrm{Na}$ intenção de conhecer melhor a nossa realidade frente ao sarampo, o Departamento de Epidemiologia e Controle de Doenças e o Laboratório de Pesquisas Biológicas planejaram o presente estudo com o objetivo de analisar o estado imunitário da população mais suscetível e relacioná-lo ao antecedente vacinal, idade e idade da vacinação.

\section{MATERIAL E METTODOS}

\section{População Alvo}

A população alvo foi constituída de crfanças entre 5 e 15 meses de idade que compareceram em 7 postos de saúde na cidade de Curitiba e São José dos Pinhais, Estado do Paraná, entre os meses de junho e outubro de 1983. A população estimada para as duas cidades na faixa etária considerada foi de 30.951 habitantes.

Levando-se em consideração que as cida. des de Curitiba e São José dos Pinhais são muito próximas e que a população de am. bas tem comportamento homogêneo, consideramos ñ̃o haver disparidade em estudar a população amostral em conjunto.

\section{Variáveis}

As variáveis foram definidas de maneira operacional visando maior compatibilidade com a precisđ̃o da amostra:

- idade: número de meses verificados entre 5 e 15, das crianças que compareceram aos postos de saúde;

- idade da vacinação: crianças que por ocasião da coleta certificaram a data da vacinação;

- vacinados e não-vacinados: crianças que por ocasião da coleta de sangue haviam ou não sido vacinadas;

- Trabalho realizado por R.A. Becker e R.C. Oliveira sobre "Eficácia da vacina e outros aspectos do sarampo em surto ocorrido em Planaltina, DF" - Dados inéditos. 
RODRIGUEZ, M.A.L. et al. Inquérito sorológico de sarampo em crianças de 5 a 15 meses de idade, em Curitiba e São José dos Pinhais, Estado do Paraná, Brasil, 1983. Rev. Saúde públ., S. Paulo, 18:421-8, 1984.

- crianças protegidas: aquelas que apresentaram títulos de anticorpos neutralizan. tes maiores que $1: 1$;

- crianças suscetíveis: aquelas que apresentaram títulos de anticorpos neutralizan. tes menores que $1: 1$.

\section{Método de Amostragem}

Optou-se pela amostragem aleatória sim. ples, ou seja, coletaram-se amostras de sangue de todas as crianças entre 5 e 15 meses de idade que compareceram aos 7 postos de saúde. Como não tínhamos conhecimento prévio da distribuição proporcional das crianças vacinadas e não-vacinadas na idade considerada, utilizamos a distribuição binominal assumindo que o diagnóstico mais freqüente tivesse uma proporção de 50\%, dando-nos uma menor probabilidade de erro.

\section{Tamanho da Amostra}

Utilizando-se a fórmula da variância para distribuiçðes binominais $\sigma^{2}=\frac{p q}{n}$, foi definido o valor de $n$, que é o tamanho da amostra e para tal, o intervalo de confiança desejado de $95 \%$.

Afim de compatibilizar o grau de precisão com os resultados esperados, considerou-se um erro de $6 \%$.

Se $z=\frac{E}{\sigma} ; z=$ valor tabelado para distribuiçōes normais, sendo $E=0,06$, temos que:

$\sigma \times \mathrm{z}<\mathrm{p}<\sigma \times \mathrm{z}=\alpha \Rightarrow \sigma \times 1,96<\mathrm{p}<\sigma \times$ $\mathrm{x} 1,96=0,95$

$\sigma \times 1,96=0,06 \therefore \sigma=0,0306122 \Rightarrow \sigma^{2}=$ $=9,37106 \times 10^{-4}$

$$
\text { Então } \mathrm{n}=\frac{\mathrm{p} \times \mathrm{q}}{\sigma^{\frac{2}{2}}}=\frac{0,50 \times 0,50}{9,37106 \times 10^{-4}} \times 267
$$

Tem-se que o tamanho da amostra é de 267 crianças.

Durante a coleta, foi possível coletar 377 amostras de sangue que estão descritos na Tabela 1, levando-se em consideração os dados pessoais do antecedente vacinal e da ocorrência ou não de sarampo.

T A B E L A 1

Número e percentual de crianças vacinadas e não vacinadas segundo a idade (em meses) por ocasião da coleta. Curitiba e São José dos Pinhais, Estado do Paraná, junho a outubro de 1983.

\begin{tabular}{|c|c|c|c|c|c|}
\hline \multirow{2}{*}{$\begin{array}{l}\text { Idade } \\
\text { (Meses) }\end{array}$} & \multirow{2}{*}{$\begin{array}{l}\text { Nọ } \\
\text { Total }\end{array}$} & \multicolumn{2}{|c|}{ Vacinados } & \multicolumn{2}{|c|}{ Não-Vacinados } \\
\hline & & Nọ & $\%$ & Nọ & $\%$ \\
\hline $\begin{array}{r}5 \\
6 \\
7 \\
8 \\
9 \\
10 \\
11 \\
12 \\
13 \\
14 \\
15\end{array}$ & $\begin{array}{l}37 \\
39 \\
47 \\
32 \\
36 \\
43 \\
26 \\
31 \\
39 \\
31 \\
16\end{array}$ & $\begin{array}{r}- \\
4 \\
18 \\
21 \\
28 \\
34 \\
18 \\
26 \\
32 \\
29 \\
13\end{array}$ & $\begin{array}{c}- \\
- \\
38,3 \\
65,6 \\
77,8 \\
79,1 \\
69,2 \\
83,9 \\
82,0 \\
93,5 \\
81,2\end{array}$ & $\begin{array}{r}37 \\
35 \\
29 \\
11 \\
8 \\
9 \\
8 \\
5 \\
7 \\
2 \\
3\end{array}$ & $\begin{array}{r}100 \\
89,7 \\
61,7 \\
34,4 \\
22,2 \\
20,9 \\
30,8 \\
16,1 \\
18,0 \\
6,5 \\
18,8\end{array}$ \\
\hline Total & 377 & 223 & - & 154 & - \\
\hline 8 a 15 & 254 & 201 & $79 \%$ & 53 & $21 \%$ \\
\hline
\end{tabular}


RODRIGUEZ, M.A.L. et al. Inquérito sorológico de sarampo em crianças de 5 a 15 meses de idade, em Curitiba e Sáo José dos Pinhais, Estado do Paraná, Brasil, 1983. Rev. Sáde púbh, S. Paulo, 18:421-8, 1984.

\section{Teste de Soroneutralizaça}

As amostras foram coletadas por punção digital e após a sua coagulação e clarificação, por centrifugação, foram estocados a $\cdot 309 \mathrm{C}$ até a sua utilização.

Utilizou-se a microtécnica convencional ${ }^{17}$ em placas de fundo redondo. Foram usados virus de cepa Nagahata (100 TCDI 50), celulas de linhagem Vero ( \pm 39 passagem in vitro) e soros padroes anti-sarampo*. Realizaram-se diluiçбes com fator 2 a partir do soro puro $(1: 1)$ até a concentraçắo de $1: 128$. A leitura final foi feita a partir do 60 dia de incubaçđ̃o.

\section{RESULTADOS}

A Tabela 1 mostra a distribuição por fajxa etária das crianças vacinadas.

Das 254 crianças de 8 a 15 meses, 201 comprovaram 0 antecedente vacinal 0 que representa uma cobertura de $79 \%$. Utilizou-se esta faixa etária para avaliar a cobertura vacinal, porque a Secretaria de Saúde do $\mathrm{Pa}$ - raná preconiza a vacinação ao 79 mês.

$\mathrm{Na}$ Tabela 2 apresenta-se o percentual de protegidos (títulos de anticorpos maior ou igual a 1:1) nas diferentes faixas etárias das crianças vacinadas.

Na Tabela 3 verifica-se que entre o 7 o e - 10 o més de idade o percentual médio de protegidos é de $44 \%$ e entre o 11 o e o 150 mês é de $65,1 \%$. Ao testarmos, pelo método de "significância da diferença entre duas proporçōes - indice t", se os percentuais apresentados independente das freqüências amostradas eram significativos, obteve-se o seguinte resultado:

$d=21,1$ - diferença entre as proporçóes

$E_{p}=6,89$ - erro padrăo

$T=3,06$

A diferença entre as duas proporçoes é estatisticamente significativa, pois esta é maior que três vezes o erro padrão, ou seja, comprova-se que as crianças entre o 11 ! e 150 més de idade apresentam maior proporção de protegidos.

Na Tabela 4 apresenta-se os percentuais

TA B E A 2

Número de crianças vacinadas segundo idade por ocasiato da coleta da amostra e títulos de anticorpos neutralizantes e percentuais de proteção. Curitiba e São Još́ dos Pinhais, Estado do Paraná, junho a outubro de 1983.

\begin{tabular}{|c|c|c|c|c|c|c|c|c|c|c|c|c|}
\hline \multirow{2}{*}{$\begin{array}{c}\text { Idade } \\
\text { (Meses) }\end{array}$} & \multirow{2}{*}{$\begin{array}{c}\text { No } \\
\text { Total }\end{array}$} & \multirow{2}{*}{$\frac{\begin{array}{c}\text { Náo } \\
\text { Proteg. }\end{array}}{<_{1: 1}}$} & \multicolumn{10}{|c|}{ Protegidos } \\
\hline & & & $1: 1$ & $1: 2$ & $1: 4$ & $1: 8$ & $1: 16$ & $1: 32$ & $1: 64$ & $1: 128$ & Total & $\%$ \\
\hline $\begin{array}{r}7 \\
8 \\
9 \\
10 \\
11 \\
12 \\
13 \\
14 \\
15\end{array}$ & $\begin{array}{l}17 \\
22 \\
28 \\
33 \\
17 \\
23 \\
29 \\
26 \\
14\end{array}$ & $\begin{array}{r}10 \\
12 \\
16 \\
18 \\
6 \\
5 \\
9 \\
11 \\
7\end{array}$ & $\begin{array}{c}1 \\
1 \\
1 \\
- \\
2 \\
1 \\
4 \\
-1\end{array}$ & $\begin{array}{l}2 \\
2 \\
1 \\
4 \\
2 \\
5 \\
3 \\
1 \\
1\end{array}$ & $\begin{array}{l}2 \\
3 \\
2 \\
1 \\
2 \\
3 \\
3 \\
1 \\
3\end{array}$ & $\begin{array}{r}2 \\
2 \\
5 \\
5 \\
- \\
3 \\
4 \\
7 \\
-\end{array}$ & $\begin{array}{l}- \\
2 \\
1 \\
2 \\
3 \\
5 \\
2 \\
3 \\
2\end{array}$ & $\begin{array}{c}- \\
- \\
2 \\
2 \\
2 \\
1 \\
3 \\
2 \\
-\end{array}$ & $\begin{array}{l}- \\
- \\
- \\
- \\
- \\
- \\
1 \\
1 \\
-\end{array}$ & $\begin{array}{l}- \\
- \\
\overline{1} \\
- \\
- \\
- \\
- \\
-\end{array}$ & $\begin{array}{r}7 \\
10 \\
12 \\
15 \\
11 \\
18 \\
20 \\
15 \\
7\end{array}$ & $\begin{array}{l}41,2 \\
45,5 \\
42,9 \\
45,4 \\
64,7 \\
78,3 \\
69,0 \\
57,7 \\
50,0\end{array}$ \\
\hline Total & 209 & 94 & 11 & 21 & 20 & 28 & 20 & 12 & 2 & 1 & 115 & 55,0 \\
\hline
\end{tabular}

- Gentilmente cedidos pelo Dr. Akira Homa do Biomanguinhos da Fundaçāo Oswaldo Cruz, Rio de Janeiro. 
RODRIGUEZ, M.A.L. et al. Inquérito sorológico de sarampo em crianças de 5 a 15 meses de idade, em Curitiba e Sáo José dos Pinhais, Estado do Paraná, Brasil, 1983. Rev. Saúde públ, S. Paulo, 18:421-8, 1984.

\section{T A B E L A 3}

Número de crianças vacinadas segundo idade por ocasião da coleta da amostra, títulos de anticorpos neutralizantes e percentuais de proteção. Curitiba e São José dos Pinhais, Estado do Paraná, junho a outubro de 1983

\begin{tabular}{|c|c|c|c|c|c|}
\hline \multirow{2}{*}{$\begin{array}{c}\text { Idade } \\
\text { (Meses) }\end{array}$} & \multirow{2}{*}{$\begin{array}{l}\text { Nọ } \\
\text { Total }\end{array}$} & \multicolumn{2}{|c|}{ Nธ̃o-Protegidos } & \multicolumn{2}{|c|}{ Protegidos } \\
\hline & & Nọ & $\%$ & Nọ & $\%$ \\
\hline $\begin{array}{r}7 \text { a } 10 \\
11 \text { a } 15\end{array}$ & $\begin{array}{l}100 \\
109\end{array}$ & $\begin{array}{l}56 \\
38\end{array}$ & $\begin{array}{l}56,0 \\
34,9\end{array}$ & $\begin{array}{l}44 \\
71\end{array}$ & $\begin{array}{l}44,0 \\
65,1\end{array}$ \\
\hline
\end{tabular}

T A B E L A 4

Número de crianças não vacinadas segundo idade, por ocasiâo da coleta da amostra, títulos de anticorpos neutralizantes e percentual de proteção. Curitiba e São José dos Pinhais, Estado do Paraná, junho a outubro de 1983.

\begin{tabular}{|c|c|c|c|c|c|c|c|c|c|c|}
\hline \multirow{2}{*}{$\begin{array}{c}\text { Idade } \\
\text { (Meses) }\end{array}$} & \multirow{2}{*}{$\begin{array}{l}\text { No } \\
\text { Total }\end{array}$} & \multirow{2}{*}{$\frac{\begin{array}{c}\text { Não } \\
\text { Proteg. }\end{array}}{<1: 1}$} & \multicolumn{8}{|c|}{ Protegidos } \\
\hline & & & $1: 1$ & $1: 2$ & $1: 4$ & $1: 8$ & $1: 16$ & $1: 32$ & Total & $\%$ \\
\hline 5 & 37 & 16 & 4 & 7 & 9 & 1 & - & - & 21 & 56,7 \\
\hline 6 & 35 & 25 & 4 & 4 & 2 & - & - & - & 10 & 28,6 \\
\hline 7 & 27 & 23 & 1 & 3 & - & - & - & - & 4 & 14,8 \\
\hline 8 & 9 & 7 & - & - & 1 & - & - & 1 & 2 & 22,2 \\
\hline 9 & 8 & 7 & 1 & - & - & - & - & - & 1 & 12,5 \\
\hline 10 & 9 & 5 & - & 1 & - & 3 & - & - & 4 & 44,4 \\
\hline 11 & 6 & 5 & - & - & 1 & - & - & - & 1 & 16,7 \\
\hline 12 & 3 & 3 & - & - & - & - & - & - & - & - \\
\hline 13 & 7 & 5 & - & - & - & 1 & 1 & - & 2 & 28,6 \\
\hline 14 & 2 & 2 & - & - & - & - & - & - & - & - \\
\hline 15 & 2 & 2 & - & - & - & - & - & - & - & - \\
\hline
\end{tabular}

de protegidos nas diferentes faixas etárias das crianças não vacinadas. Neste grupo o percentual de protegidos do 50 ao 90 mês caiu de $56,7 \%$ para $12,5 \%$ (Fig. 2).

$\mathrm{Na}$ Tabela 5 observa-se o percentual das crianças que comprovaram a idade de vacinação em relação aos títulos de anticorpos. De 173 crianças vacinadas, 97 (56,07\%) apresentaram títulos de anticorpos protetores.

A Tabela 6 mostra que de 120 crianças vacinadas, no 70 e 80 mês, $61(50,83 \%)$ apresentaram títulos protetores de anticorpos e que de 33 crianças vacinadas, entre o 90 e 12 \% mês, $25(75,75 \%)$ apresentaram títulos protetores.

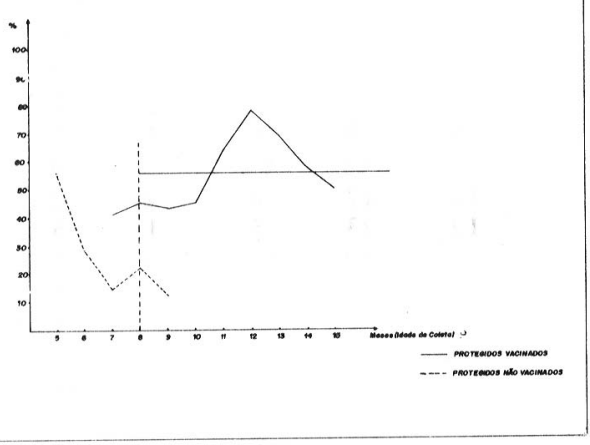

Fig. 2 - Percentual de protegidos vacinados e não vacinados segundo idade por ocasião da coleta, na cidade de Curitiba e São José dos Pinhais - 1983. 
RODRIGUEZ, M.A.L. et al. Inquérito sorológico de sarampo em crianças de 5 a 15 meses de idade, em Curitiba e Sáo José dos Pinhais, Estado do Paraná, Brasil, 1983. Rev, Saúde públ, S. Paulo, 18: 421-8, 1984.

TA B E L A 5

Número e percentual de crianças, segundo a idade da vacinação, com relação aos títulos de anticorpos e percentual de protegidos. Curitiba e São José dos Pinhais, Estado do Paraná, junho a outubro de 1983.

\begin{tabular}{|c|c|c|c|c|c|c|c|c|c|c|c|}
\hline \multirow{2}{*}{$\begin{array}{l}\text { Idade da } \\
\text { Vacina- } \\
\text { çá } \\
\text { (Meses) }\end{array}$} & \multirow{2}{*}{$\begin{array}{l}\text { No } \\
\text { (\%) }\end{array}$} & \multirow{2}{*}{$\frac{\begin{array}{c}\text { N2o } \\
\text { Proteg. }\end{array}}{\frac{<1: 1}{<}}$} & \multicolumn{9}{|c|}{ Protegidos } \\
\hline & & & $1: 1$ & $1: 2$ & $1: 4$ & $1: 8$ & $1: 16$ & $1: 32$ & $1: 64$ & Total & $\%$ \\
\hline $\begin{array}{r}6 \\
7 \\
8 \\
9 \\
10 \\
11 \\
12\end{array}$ & $\begin{array}{r}20(11,5) \\
82(47,4) \\
38(22,0) \\
14(8,1) \\
9(5,2) \\
9(5,2) \\
1(0,6)\end{array}$ & $\begin{array}{r}9 \\
43 \\
16 \\
3 \\
3 \\
2 \\
-\end{array}$ & $\begin{array}{l}2 \\
5 \\
3 \\
1 \\
2 \\
- \\
-\end{array}$ & $\begin{array}{l}1 \\
7 \\
4 \\
3 \\
- \\
- \\
-\end{array}$ & $\begin{array}{r}4 \\
8 \\
2 \\
- \\
- \\
2 \\
-\end{array}$ & $\begin{array}{r}2 \\
11 \\
6 \\
4 \\
- \\
1 \\
-\end{array}$ & $\begin{array}{l}1 \\
5 \\
3 \\
1 \\
1 \\
4 \\
1\end{array}$ & $\begin{array}{l}1 \\
2 \\
4 \\
1 \\
3 \\
- \\
-\end{array}$ & $\begin{array}{l}\overline{1} \\
\overline{1} \\
\overline{-} \\
\overline{-}\end{array}$ & $\begin{array}{r}11 \\
39 \\
22 \\
11 \\
6 \\
7 \\
1\end{array}$ & $\begin{array}{l}55,0 \\
47,6 \\
57,9 \\
78,6 \\
66,7 \\
77,7 \\
-\end{array}$ \\
\hline Total 1 & 173 & 76 & 13 & 15 & 16 & 24 & 16 & 11 & 2 & 97 & 56,1 \\
\hline
\end{tabular}

T A B E L A 6

Número de crianças, segundo a idade da vacinação, com relação aos percentuais de protegidos e não protegidos. Curitibá e São José dos Pinhais, Estado do Paraná, junho a outubro de 1983.

\begin{tabular}{|c|c|c|c|c|c|c|}
\hline \multirow{2}{*}{$\begin{array}{l}\text { Idade da } \\
\text { Vacinaçã̄o } \\
\text { (Meses) }\end{array}$} & \multirow{2}{*}{ No } & \multicolumn{2}{|c|}{ Nz̃o Protegidos } & \multicolumn{3}{|c|}{ Protegidos } \\
\hline & & Nọ & $\%$ & No & $\%$ & MG \\
\hline 79 a 89 & 12 & 59 & 49,2 & 61 & 50,8 & 5,3 \\
\hline $\begin{array}{c}90,100 \\
1190120 \\
\end{array}$ & 33 & 8 & 24,2 & 25 & 75,7 & 8,6 \\
\hline
\end{tabular}

MG : média geométrica dos títulos.

Aplicando o método de "significância entre duas proporçōes - indice $t$ " tem-se que: $d=24,2$

$E_{p}=6,72$

$T=3,60$, onde conclui-se que a diferença entre os $50,8 \%$ no 70 e 80 més é estatisticamente significativa com relação aos $75 \%$ do 90 ao 11 ̣̂̀s de idade. A média geométrica dos títulos das crianças vacinadas até o 8 ? mês é de 5,3 e do 90 ao 120 mês é de 8,6 .

\section{DISCUSSAOO E CONCLUSOES}

Como se observa na Tabela 1 , aos 7 me. ses de idade a cobertura vacinal é de $38,3 \%$, ao 80 mês $65,5 \%$ e, assim, os percentuais de protegidos aumentam até o 14 \% mês com 93,5\%. Já que o Estado do Paraná propóe como idade de vacinação o 7 ̣̣ mês, avaliamos qual a cobertura vacinal em 254 crianças entre 80 e 150 mês de idade, encontran. do $79 \%$, ou seja, inferior aos $100 \%$ calcula. do pelo programa de imunização do Estado.

As crianças vacinadas, com idade de 7 a 10 meses (por ocasifo da coleta), apresentavam percentuais de proteção significativamente inferior ao grupo com idade entre 11 e 15 meses (Tabelas 2 e 3). Resultados se. melhantes foram observados pelos mesmos autores em inquérito sorológico realizado na mesma região no ano de 1982*. Este fato po.

* Dados inéditos 
RODRIGUEZ, M.A.L. et al. Inquérito sorológico de sarampo em crianças de 5 a 15 meses de idade, em Curitiba e São José dos Pinhais, Estado do Paraná, Brasil, 1983. Rev. Saúde públ, S. Paulo, 18:421-8, 1984.

deria ser explicado por uma resposta imune mais intensa uma taxa maior de protegidos que ocorre nos vacinados após o 90 mês. Outro fator que poderia estar influenciando nesses resultados seria a existência de sarampo endêmico na região, levando a grande circulação do virus selvagem.

Esta exposição ao virus selvagem poderia elevar o título dos anticorpos protetores e aumentar a percentagem de crianças protegidas após o 10 ̣̂ mês, já que no grupo de crianças não-vacinadas maiores de 10 meses (onde é pouco provável a presença de anticorpos passivos), $21,7 \%$ apresentam anticorpos anti-sarampo.

Os percentuais decrescentes de protegidos do 50 ao 9 ̣ mês (Fig. 2), nas crianças não-vacinadas, mostram a esperada queda dos anticorpos passivos.

O objetivo de se aplicar a vacina anti-sarampo no 70 mês de idade era reduzir a in. cidência da doença em idades onde a mortalidade é maior. Entretanto observamos que com a atual política de vacinação somente $44 \%$ dos vacinados no grupo até 10 meses apresentaram títulos de anticorpos considerados protetores.

Comparando-se a resposta obtida nas crianças vacinadas aos $70^{\circ}$ e 8 ? meses com aquelas vacinadas a partir do 99 mês, observamos uma resposta nitidamente maior nas vacinadas mais tardiamente.

Considerando que a população estimada para o grupo etário de 7 meses a 4 anos é de 127.919 crianças nas duas cidades em estudo, e supondo que $100 \%$ das crianças fossem vacinadas nos 70 e 80 meses de vida (neste estudo é de $80,9 \%$ ) com um percentual de proteção induzido pela vacina de $50,8 \%$, teríamos então 61.657 crianças desprotegidas. Se levarmos em conta que a população vacinada após o 9 o mês apresenta $75 \%$ de protegidos esperarramos 36.328 desprotegidos, nesta mesma população (este número é resultante da soma dos $25 \%$ de crianças desprotegidas, a partir do 90 més e de $100 \%$ da população de crianças de 7 e 8 meses), ou seja, significaria uma redução de $41,0 \%$ no total de crianças desprotegidas. Além desta estimativa deve-se considerar o fato de que a média geométrica dos títulos é maior nos vacinados a partir do 90 mês e, assim, a imunidade mais duradoura.

Em base ao exposto propomos a vacinação ao 99 mês, e recomendamos avaliação da resposta imune da populaçđo estudada após um ano de implantaçđo deste novo esquema.

RODRIGUEZ, M.A.L. et al. [Serological survey on measles in children of five to fifteen months of age, in Curitiba and S. José dos Pinhais, State of Paraná, Brazil - 1983] Rev. Saúde públ., S. Paulo, 18: 421-8, 1984.

ABSTRACT: A serological survey intended to evaluate the causes of the high incidence of frequent outbreaks of measles in the cities of Curitiba and S. José dos Pinhais, Paraná, shows that of children vaccinated between 7 and 10 months of age, only $44 \%$ are protected, whereas in those vaccinated between the 11 th and 15 th months, the level of protection rises to $65.1 \%$. Samples taken in non-vaccinated children at the 5 th, 6 th and 7 th months of age showed protection level of $56.7 \%, 28.6 \%$ and $14.8 \%$ respectively. The children vaccinated during the 7 th and 8 th months of age had a percentage of protection of 50.8 , and those vaccinated from the 9 th month on, a percentage of 75.75 . The geometric averages of antibody titers are also lower in those vaccinated before 9 months of age as compared to those vaccinated after this age.

UNITERMS: Measles, prevention and control. Serological surveys. 
RODRIGUEZ, M.A.L. et al. Inquérito sorológico de sarampo em crianças de 5 a 15 meses de idade, em Curitiba e São José dos Pinhais, Estado do Paraná, Brasil, 1983. Rev. Saúde públ., S. Paulo, 18: 421-8, 1984.

\section{REFERENCIAS BIBLIOGRÅFICAS}

1. ABLBRECHT, P.; ENNIS, F.A.; SALTZMAN, E.J. \& KRUGMAN, S. Persistence of maternal antibody in infants beyond 12 months: mechanism of measles vaccine failure. J. Pediatr., $91: 715-8,1977$.

2. ALVIM, E. \& MESQUITA, J.F. Estudo do custo-efeito do controle do sarampo. Rev. Fund. SESP, 24:26-31, 1979.

3. BURGASOV, P.N.; ANDZAPARIDZE, D.G. \& POPOV, V.F. The status of measles after five years of mass vaccination in the URSS. Bull. Wld Hlth Org., 49: 571-6, 1973.

4. CALDERON, E.; MARTINSOSA, S.; MILO VANOVIC, M.V. \& ALVAREZ, A. Immunidad contra el sarampión en binomios madre-hijo. Bol. med. Hosp. infant., 34: $1-12,1977$.

5. CONFUSION and clarification of current recommendations for measles vaccination. J. Pediatr., 91 : 846-7, 1977.

6. FOEGE, W.H. Programas de vacunacion contra el sarampión en África Ocidental. Bol. Ofic. sanit. panamer., 77: 500-8, 1974.

7. FULGINITI, V. Commentary: measles immunization. J. Pediatr., 94: 1019-20, 1979.

8. FULGINITI, V.A. Immunizations: current controversies. J. Pediatr., 101: 487-94, 1982.

9. KATZ, S.L. Sarampo: a situação mundial. Soúde Mundo, p. 14-5, dez. 1982.

10. KIMATI, V.P.; LORETU, K.; MUNUBE, G. M.R. \& KIMBOI, F. The problems of measles virus response with reference to vaccine viability, age, protein energy, malnutrition and malaria in the tropics. J. trop. Pediatr., 27: $205-9,1981$.
11. KRUGMAN, S.; GILES, J.P.; FRIEDMAN, H. \& STONE, S. Studies on immunity, to measles. J. Pediatr., 66: 471-80, 1965.

12. MARTINS, R.M. Sarampo. In: Farhat, C.R. Fundamentos e práticas das imunizaçōes São Paulo, Medisa Ed., 1980. p. 207.36.

13. MEASLES immunity in the just year after birth an optimun age for vaccination in Kenyan children: collaborative study by the Ministry of Health of Kenya and the World Health Organization. Bull. Wld Hlth Org., 55: 21-30, 1977.

14. PLOTKIN, S.A. Failures of protection by measles vaccine. J. Pediatr., 82: 908-11, 1973.

15. RUIZ-GOMES, J.P.; SANCHES-BURGOS, Y.; ALVAREZ-ROMERO, P.F.; ARRAYALES, F. Respuesta a la vacuna anti sarampion al ser aplicada a diferentes idades. Salud publ. México, 20: 239-42, 1978.

16. TAXAS de soroconversão e títulos de anticorpos de sarampo induzidos pela vacina anti-sarampo em crianças da América Latina de 6-12 meses de idade. Estudo realizado em colaboração pelos Ministérios da Saúde do Brasil, Chile, Costa Rica, Equador e Organização Panamericana de Saúde. Bol. epidemiol., 14:69-83, 1982.

17. UEDA, S. Comparison of measles antibody titers measured by the micro and macro methods. Biken J., 14: 155-60, 1971.

18. WILKINS, J. \& WEHRLE, P.F. Additional evidence against measles vaccine administration to infants less than 12 months of age: altered immune response following active/passive immunization. J. Pediatr., $94: 865-9,1979$.

19. YEAGER, A.S.; DAVIS, J.H.; ROSS, L.A. \& HARVEY, B. Measles immunization success and failures. $J$. Amer. med. Ass, 237: 347-51, 1977.

Recebido para publicação em 06/07/1984. Aprovado para publicaçāo em 09/11/1984. 